\title{
Makine Öğrenmesi Metodolojisi Kullanılarak Yüksek Hızlı Rulmanlarda Sağlık Göstergesinin Belirlenmesi
}

\author{
Erkan Caner Özkat ${ }^{1 *}$ \\ 1* Recep Tayyip Erdoğan Üniversitesi, Mühendislik Mimarlık Fakültesi, Makine Mühendisliği Bölümü, Rize, Türkiye, (ORCID: 0000-0003-0530-5439), \\ erkancaner.ozkat@erdogan.edu.tr
}

(İlk Geliş Tarihi Aralık 2020 ve Kabul Tarihi Ocak 2021)

(DOI: $10.31590 /$ ejosat.843465)

ATIF/REFERENCE: Ozkat, E. C. (2021). Makine Öğrenmesi Metodolojisi Kullanılarak Yüksek Hızlı Rulmanlarda Sağlık Göstergesinin Belirlenmesi. Avrupa Bilim ve Teknoloji Dergisi, (22), 176-183.

\begin{abstract}
Öz
Makine sağlı̆̆ı göstergesi, bir makine parçasının bozulma aşamalarını ve ortaya çıkacak nihai arızasını gösterir. Bu çalışmanın temel amacı, makine öğrenmesi metodolojisi kullanarak titreşim verilerinden makine sağlığı göstergesini belirlemektir. Tespit edilen bu sağlık göstergesi daha sonra kalan faydalı ömür tahminde kullanılacaktır. Makine sağlık göstergesini hesaplamak için gerekli adımlar, özellik çıkarma, normalleştirme ve temel bileşen analizi olarak listelenmiştir. Bu çalışmada titreşim sinyalleri zaman alanından frekans alanına Welch yöntemi kullanılarak dönüştürülmüş ve ardından sıralanan öznitelikler basıklık, çarpıklık, etkin değer, tepe faktörü ve etki faktörü hesaplanmış. Özniteliklerin gürültüsü z-skor ve Savitzky-Golay yöntemleri kullanılarak azaltılmıştır. Sonrasında, temel bileşen vektörlerini hesaplamak için düzeltilmiş özniteliklere temel bileşen analizi uygulanmıştır. Bu vektörlerden monoton eksponansiyel artış eğilimine en iyi uyan vektörler kullanışlı temel bileşen vektörlerdir. Sağlık göstergesi, faydalı temel bileşen vektörlerinin ortalama değeridir ve kalan faydalı ömrü tahmin etmek için kullanılmıştır. Tahminin başarısı determinasyon katsayısı $\left(\mathrm{R}^{2}\right)$ ve kök ortalama kare hata (RMSE) değerleri ile belirlenmiştir. Sonuçlara göre, $\mathrm{R}^{2}$ ve RMSE değerleri: prior eğitim seti için sırayıla 0.6625 ve 17.8925 ; posterior eğitim seti için sırayıla 0.9947 ve 1.7688 ; test seti için sırayıla 0.9897 ve 2.2025 'tir.
\end{abstract}

Anahtar Kelimeler: Kestirimci Bakım, Makine Ögrenmesi, Sağlık Göstergesi, Temel Bileşen Analizi, Mekanik Titreşimler.

\section{Determination of Health Indicator in High Speed Bearings Using Machine Learning Methodology}

\begin{abstract}
The machine health indicator shows the deterioration stages of a machine part and its failure. The main purpose of this study is to determine the machine health indicator from vibration data using machine learning. The determined health indicator will then be used in the remaining useful life estimation. The necessary steps to calculate the indicator are listed as feature extraction, normalization, and principal component analysis. In this study, vibration signals are transformed from time domain to frequency domain using the Welch method then the listed features kurtosis, skewness, effective value, crest factor and impact factor are calculated. The noise of these features has been reduced utilizing z-score and Savitzky-Golay methods. Subsequently, principal component analysis is applied to compute principal component vectors. Of these vectors, vectors that best match the monotone exponential upward trend are chosen as useful principal component vectors. The health indicator is the mean value of the useful principal component vectors and it has been used to estimate the remaining useful life. The success of the prediction is determined by the determination coefficient $\left(\mathrm{R}^{2}\right)$ and root mean square error (RMSE) values. According to the results, $\mathrm{R}^{2}$ and RMSE values are: 0.6625 and 17.8925 for the prior training set, respectively; 0.9947 and 1.7688 for posterior training set, respectively; for the test set it is 0.9897 and 2.2025 , respectively.
\end{abstract}

Keywords: Predictive Maintenance, Machine Learning, Health Indicator, Principal Component Analysis, Mechanical Vibrations.

\footnotetext{
*Sorumlu Yazar: erkancaner.ozkat@erdogan.edu.tr
} 


\section{Giriş}

Kestirimci bakım, bir makinenin sağlık durumunu tahmin etme ve sensörler yardımıyla toplanan verileri/ölçümleri makine öğrenimi yöntemleriyle entegre ederek bakım eylemleri hakkında en iyi kararı verme süreci olarak tanımlanır. Ayrıca, kestirimci bakım ile arızayı başlangıç aşamasında tespit edildiğinden, zincir hasarları ve yıkıcı arızalar olasılığını azaltılır ve bakım planlamasında ve hangi parçaların düzeltilmesi gerektiğinin belirlenmesine yardımcı olur. Buna ek olarak, ekipmanın gelecekteki koşulu veya kalan faydalı ömrü için bir tahmin de verebilir.

Son yıllarda teknolojinin gelişmesine bağlı olarak, birçok kestirimci bakım çalışmasında sıcaklık, basınç, yağ kalitesi, gürültü ve titreşim sensör verileri kullanılmaktadır. Hangi sensör verisinin kullanılacağına ilişskin karar hem incelenecek sorunun türüne hem de makinenin çalışma koşullarına bağlıdır. Dönen ekipmanların çeşitli nedenlerle yük altında olması ve zorlanması, makinelerde güç tüketimini etkileyen ana faktörlerden biridir. Titreşim analizi, endüstride her tür dönen ekipman için kullanılan en yaygın durum izleme teknolojisidir ve rulman arızalarını teşhis etmek için etkili bir araçtır. Çünkü titreşim makinenin çalışmasını engelleyecek ve hatta rezonans ile makinenin tahrip olmasına yol açacaktır.

Rulman arızalarını etkili bir şekilde tespit etmek ve titreşim davranışlarının tam olarak anlaşılması için gelişmiş titreşim tabanlı algoritmalar geliştirmek gerekir. Literatürde makinelerde rulman arızasına yol açabilecek kusurları önceden tespit edip giderebilmeye yönelik çeşitli yöntemler anlatılmıştır. Bu titreşim analizi yöntemleri, zaman tabanlı, frekans tabanlı ve zamanfrekansa tabanlı yaklaşımlar olarak sınıflandırılabilir.

Tao vd. (2020) tarafından yürütülen bir çalışmada; dönen makinalarda yataklarda yuvarlanan elemanların durumunu belirlemek için Fourier ve Ayrık Dalgacık dönüşümü kullanılmış, önceden işlenen sinyaller birkaç seviyeye ayrılarak hatalı ve sağlıklı rulmanlar arasında bir sinıflandırma gerçekleştirmiştir. Sun vd. (2013) ayrık dalgacık dönüşümü ve zarf analizi yöntemlerini birleştirerek rulmanlı yatak titreşim verilerinden bir spektrum çıkarmayı hedeflemiştir. Rulmanlardaki farklı arızaları teşhis etmek için kullanılan yöntemin yüksek performans ve doğruluk gösterdiği tespit etmiştir. Oldukça güçlü bir analiz yöntemi olan zarf analizi; yüksek frekanslı rezonans tekniği (HFRT) olarak da adlandırılır ve klasik spektrumda belirlenen rezonansları sınıflandırmak için kullanılır (Saidi vd., 2017). Ancak özellikle ana rezonansların sınıflandırılması zor bir işlemdir ve klasik spektrumda belirlenen tüm rezonansları analiz etmemiz gerektiğinden hesaplama süreleri uzayacaktır. Basıklık bu işlemi daha kolay bir hale getiren; sinyaldeki geçici akımların yerini belirlememizi sağlayan skaler bir ölçümdür. Spektral Kurtosis (SK) ise bundan yola çıkarak geliştirilen ve optimum bant frekansını belirlememizi sağlayan bir yöntemdir (Saidi vd., 2017). Villwock vd. (2008) ise elektrikli arabalardan elde edilen sinyallerin frekans cevabının hesaplanmasında Welch yöntemini kullanmış ve deneysel sonuçlar yöntemin etkinliğini ve esnekliğini ortaya koymuştur. Bektaş (2020) ise havacılık alanında verilerin değerlendirilmesinde Welch metodu vasıtasıyla oluşturulan alt veri setlerinde titreşime dayalı olarak hesaplamayı ve fourier dönüşüm sonuçlarıyla gözlem yapabilmeyi hedeflenmiştir. Öznitelik çıkarımı; ölçülmüş verilerden elde edilen bir başlangıç veri seti girdi olarak kullanılarak bazı türetilmiş değerler (“öznitelikler”) oluşturulmasıdır. Basıklık faktörü, çarpıklık, ortalama değer, standart sapma, tepe faktörü, şekil faktörü, etki faktörü, marjinal faktörü ve tepe noktasından zirve noktasına (pikten pike) literatürde sıklıkla kullanılan özniteliklerdir (Ali vd., 2018; Muratet vd., 2014; Villwock vd., 2008). Bu özniteliklerin çıkarımı için farklı yöntemlerden faydalanılmıştır. Liu vd. (2014), yerel ortalama dekompozisyon teknolojisini kullanarak; bir makaralı yatağın durağan olmayan titreşim sinyalini bir dizi ürün fonksiyonuna ayrıştırmayı ve her ürünün büyük ölçekte entropisine ait fonksiyonun öznitelik vektörü olarak hesaplanmasını sağlayan bir hata özniteliği çıkarma yöntemi önermiştir. Yöntemin etkinliği ise pratik yatak titreşim sinyallerinden elde edilen analiz sonuçları ile kanıtlanmıştır. Guo vd. (2014) ise, rulmanlı yatak üzerinde öznitelik çıkarımı için bir zarf çıkarma ve bağımsız bileşen analizi (ICA) yöntemlerinin kombinasyonunu kullanmıştır. Ali vd. (2018), rüzgâr türbinlerinde yüksek hızlı şaft rulmanlarında yürüttükleri çalışmada öznitelik çıkarımı için geleneksel istatistiksel özniteliklerden faydalanmıştır.

Kestirimci bakımının amacı makinenin kalan faydalı ömrünü (KFÖ) (“remaining useful life”) tahmin etmektir. KFÖ hatanın erken tespitinin sağlanması, bakım planlarının düzenlenmesi bu sayede işletim maliyetlerinden tasarruf edilmesi açısından oldukça önemlidir (Elasha vd., 2019; Teng vd., 2017; Tibaduiza vd., 2011). Genel olarak, KFÖ'ü tahmin etmek için üç model vardır: (i) hayatta kalma modeli; yalnızca arıza zamanına ait veriler bilindiğinde, (ii) bozulma modeli; arıza verileri mevcut olmadığında, ancak arızayı gösteren bir güvenlik eşiği bilindiğinde ve (iii) benzer modeli: makinelerin tam geçmişi yani sağlıklı durumundan arızaya kadar olan tüm veriler bilindiğinde (Ozkat, 2019).

$\mathrm{Bu}$ çalışmanın ana amacı, kestirimci bakım bozulma modelinde kullanılmak üzere makine öğrenmesi metodolojisi kullanılarak sağlık göstergesinin tespitir. $\mathrm{Bu}$ çalışma dört bölümden oluşmaktadır. İkinci bölüm, kullanılan materyal ve metotla ile ilgili çalışmalar incelenecektir. Takip eden bölüm ise veri setine metodun uygulanmasını ve elde edilen sonuçların analizini içermektedir. Son kısım ise önerilen çalışmanın kısıtları ve potansiyel kullanım önerilerini içermektedir.

\section{Materyal ve Metot}

\subsection{Deney Düzeneği ve Veri Seti}

$\mathrm{Bu}$ çalışmada kullanılan titreşim sinyalleri, $2 \mathrm{MW}$ rüzgâr türbini jeneratörüne takılan yüksek hızda çalışmak için tasarlanmış şaft yatağındaki rulmandan elde edilmiştir. $\mathrm{Bu}$ titreşim deneyi, Green Power ABD tarafından gerçekleştirilmiş ve deny sonuçları açık kaynak olacak şekilde araştırmacılara sunulmuştur (Ali vd., 2017; Saidi vd., 2017). Bu deneyde, iç çap1 $200 \mathrm{~mm}$, bore çap1 $100 \mathrm{~mm}$, toplam uzunluğu $56 \mathrm{~mm}$ ve $16^{\circ}$ açıya sahip olan 32222-J2-SKF konik rulman kullanılmıştır. Deney koşulları sayesinde 50 gün boyunca her gün 6 saniyelik bir titreşim sinyali toplanmıştır. Titreşim verileri $32 \mathrm{kHz}$ bant genişliğine ve $22 \mathrm{kHz}$ 'de rezonansa sahip bir MEMS ivmeölçer ile ölçülmüştür. Sensör, dişli kutusu yatak desteğinin üzerine yüksek hız miline radyal olarak monte edilmiş ve şafta dik olarak titreşimi sinyalleri alınmıştır. Şekil 1'de Green Power ABD tarafından gerçekleştirilen deney düzeneği ve rulman iç yuvasında meydana gelen arıza gösterilmiştir. 


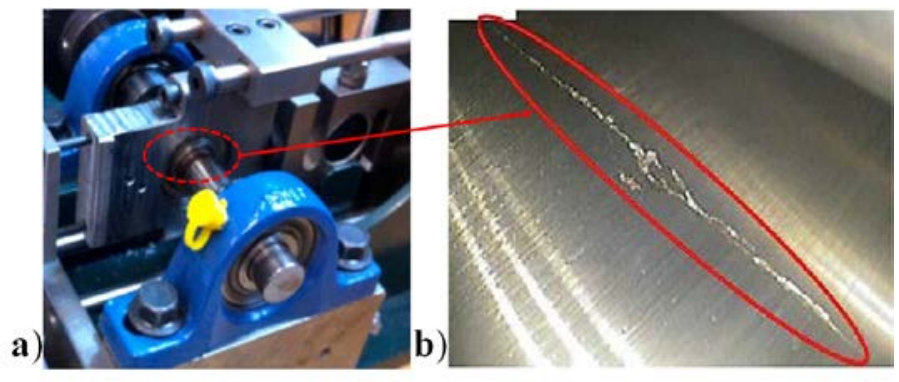

Şekil 1. Deney düzeneği a) Yüksek hizda dönen rulman, b) Rulman iç yuvasında meydana gelen arıza (Ali vd., 2017; Saidi $v d .$, 2017).

\subsection{Metot}

$\mathrm{Bu}$ çalışmanın temel amacı meydana gelen bozulmayı makine öğrenmesi metodolojisi kullanarak sağlık göstergesinde karakterize edilme bilmektir. Tespit edilen bu sağlık göstergesi daha sonra kalan faydalı ömür tahminde kullanılacaktır. Sağlık göstergesi hesaplamak için gerekli işlem adımları (i) öznitelik çıkarma, (ii) normalizasyon, (iii) temel bileşenlerin tespiti ve (iv) sağlık göstergesinin elde edilmesi şeklinde sıralanmaktadır.

\subsection{1. Öznitelik çıkarma}

Ham titreşim sinyallerden faydalı bilgilerin çıkarılması prosedürü, özellik çıkarmadır. Rulmanlar genellikle zorlu çevre koşulları altında çalışır ve bu nedenle birkaç tür hataya maruz kalırlar. Mekanik titreşimlerin analizinde ivmeölçerler tarafından zaman alanında toplanan titreşim sinyali, hataya duyarlı özellikleri ayıklamak ve yararlı bilgileri elde etmek için frekans alanı başta olmak üzere farklı alanlara dönüştürülür. $\mathrm{Bu}$ çalışmada, Welch yöntemi kullanılarak titreşim sinyalleri zaman alanından frekans alanına dönüştürülmüştür.

Welch yöntemi (Akçay \& Türkay, 2019; Jin vd., 2019), hızlı Fourier dönüşümü temelli bir yöntem olup güç spektral yoğunluğunu elde etmek için kullanılır. Welch yöntemine göre, zaman alanındaki titreşim sinyali belirli bölümlere (pencerelere) ayrılır. Daha sonra her bölümün iyileştirilmiş periyodogramı alınıp, elde edilen bu bölümlere ait periyodogramların ortalaması alınarak güç spektral yoğunluğu bulunur. İyileştirilmiş periyodogramların ortalaması tüm verinin tek bir periyodogram kestirimine göre varyansını azaltır. Fakat, bölümlerin uzunluğunun önceden kestirilmesi zordur, bölümün uzunluğu artıkça güç spektral yoğunluğu daha düz bir hale ("smooth”) gelmektedir.

İstatistiksel öznitelikler, arıza meydana geldiğinde makine titreşim sinyallerinin değişimini karakterize eden güçlü bir araçtır (Liu \& Zhang, 2020). Bununla beraber, istatistiksel özniteliklerin çıkarmanın basitliği, düşük hesaplama süresi ve hem frekans alanında hem de zaman alanında doğrudan kullanılabilmektedir (Elasha vd., 2019; Teng vd., 2017). Bu çalışmada kullanılan zaman alanı sinyallerinden ve güç spektrumundan türetilen istatistiksel özniteliklerle ilgili daha fazla matematiksel ayrıntı Tablo 1'de verilmiştir (Teng vd., 2017). Burada zaman veya frekans alanında örneklenen titreşim sinyalini $x(k)$, örnek indeksi $k$, toplam örnek sayısı $N_{k}$, örneklenmiş sinyalin ortalamasını $x_{m}$ ve standart sapmasını $x_{s t d}$ ile gösterilmiştir.
Tablo 1. Çalışmada kullanılan istatiksel öznitelikler

\begin{tabular}{cc}
\hline İstatiksel Öznitelik & Denklem \\
\hline Basıllk & $x_{\text {kurtosis }}=\frac{\sum_{k=1}^{N_{k}}\left(x(k)-x_{m}\right)^{4}}{\left(N_{k}-1\right) x_{\text {std }}^{4}}$ \\
Çarpıklık & $x_{\text {skewness }}=\frac{\sum_{k=1}^{N_{k}}\left(x(k)-x_{m}\right)^{3}}{\left(N_{k}-1\right) x_{\text {std }}^{3}}$ \\
Etkin Değer & $x_{r m s}=\sqrt{\frac{1}{N_{k}} \sum_{k=1}^{N_{k}}(x(k))^{2}}$ \\
Tepe Faktörü & $C F=\frac{\max (x(k))}{x_{r m s}}$ \\
Etki Faktörü & $I F=\frac{\max (x(k))}{\left(1 / N_{k} \sum_{k=1}^{N_{k}}|x(k)|\right)}$
\end{tabular}

\subsubsection{Normalizasyon}

Her bir zaman adımı için elde edilen öznitelikler farklı ölçeklerdedir. Bozulma davranışının doğruluğunu en üst düzeye çıkarmak için uygun ortak bir ölçeğe göre tüm özniteliklerin normalizasyonu gerekmektedir. $\mathrm{Bu}$ alanda yaygın olarak kullanılan z-skoru normalizasyon uygulanmış ve Denk (6) gösterilmiştir (Kappal, 2019). Burada $z(k), x(k)$ sinyallinin zskor yöntemine göre dönüştürülmüş halidir.

$$
z(k)=\frac{x(k)-x_{m}}{x_{s t d}}
$$

Tablo 1'de verilen öznitelik, arıza teşhisinde kullanılabilecek önemli bilgileri ifade eder. Ancak genellikle hataya karşı hassasiyeti artıracak gürültü içerir. Böylelikle, kalan faydalı ömür tahmininde hatalara neden olabilir. Bu nedenle, literatürde sıklıkla karşılaşılan hareketli ortalama (Banerjee vd., 2020), hareketli medyan (Kollmann vd., 2020) ve Savitzky-Golay (Abdelli vd., 2020) yöntemleri kullanılarak özniteliklere düzeltme işlemi uygulanır. Sinyal eğilimini bozmadan verilerin hassasiyetini artırmak amacıyla Savitzky-Golay yöntemi bu çalışmada esas alınmıştır. Savitzky-Golay yöntemi ile sinyal üzerine belirli genişlikte bir pencere oluşturulur ve bu pencere içerisinde bir polinomyal regreasyon yapılır. Bunu sonucunda sinyal içerisindeki gürültü uniform olarak temizlenir (Abdelli vd., 2020).

\subsubsection{Temel bileşenlerin tespiti}

Bir makinenin ve makine parçasının kalan faydalı ömrü mevcut sağlık durumundan arızaya kadar olan süre olarak tanımlanır. Uygulamada, makinenin tüm yaşam döngüsünün (başlangıçtan arızaya kadar) verileri mevcut değildir, ancak yaşam döngüsünün erken aşamasında bazı verilerin toplandığını varsaymak mantıklıdır. Buna ilave olarak makine öğrenmesindeki temel yaklaşım deneysel olarak el edilen veri setini, eğitim seti ve test seti diye ikiye bölünmesidir. Çünkü tüm veri setine yüksek uyumluluk göstermiş modeller yani veri setini gereğinden fazla iyi öğrenmiş (ezberlemiş) modeller, yeni bir örnek ile karşılaştığında yüksek hata yapmaya başlarlar. $\mathrm{Bu}$ nedenle, 50 gün boyunca toplanan titreşim sinyallerin ve Tablo 1'de bulunan özniteliklerin \%60'1 eğitim verileri olarak kabul edilmiştir. İlk önce, z-skor ile normalleştirilmiş daha sonra da Savitzky-Golay yöntemiyle düzeltilmiş tüm öznitelikleri (z) Denk.7'deki gibi bir küme altında toplayalım. 


$$
\mathbf{z}=\left\{z_{i, j}\right\} \quad i=1, \cdots, N_{i} \quad j=1, \cdots, N_{j}
$$

Burada, $i$ ölçümün yapıldığg günü, $N_{i}$ ölçümün yapıldığ 1 toplam gün sayısını, $j$ öznitelik indeksini ve $N_{j}$ toplam öznitelik sayısını ifade etmektedir. Bu çalışmada toplam gün sayısı 50 ve toplam öznitelik sayısı 4 zaman alanında ve 4 frekans alanında olmak üzere 8'dir. İkinci adım olarak herbir öznitelikler için Denk 8,9 ve 10 yardımıyla eğitim veri setinde kullanmak üzere ortalama değer ve standart sapma bulunmuştur. Burada, $N_{i}^{*}$ toplam gün sayısının \%60’ı kadarıdır.

$$
\begin{gathered}
\mathbf{z}_{\text {Train }}=\left\{Z_{i^{*}, j}\right\} \quad i^{*}=1, \cdots, N_{i}^{*} \quad j=1, \cdots, N_{j} \\
\mu_{Z_{\text {Train }, j}}=\frac{1}{N i^{*}} \sum_{i^{*}=1}^{N_{i}^{*}} Z_{i^{*}, j} \\
\sigma_{Z_{\text {Train }, j}}=\sqrt{\frac{\sum_{i^{*}=1}^{N_{i}^{*}}\left(z_{i^{*}, j}-\mu_{Z_{\text {Train }, j}}\right)^{2}}{N_{i}^{*}}}
\end{gathered}
$$

Kestirimci bakım, sinyal işleme, biyoinformatik gibi alanlarda boyut indirgenmesi için sıkça kullanılan yöntemlerden biri temel bileşen analizi (TBA)'dır (Yıldız vd., 2010). TBA'nın amacı, değişkenler arasındaki ilişkiyi tanımlamak ve tespit etmektir. Güçlü bir korelasyon varsa boyutluluğu azaltabilirsiniz. TBA yöntemi ile yüksek boyutlu orijinal veriseti maksimum varyans yönüne dönüştürülerek ifade edilebilir. Böylece yüksek boyutlu orijinal veriseti, daha küçük boyutlu bir alt uzaya yansıtılır. Ek olarak, TBA'nın bir zayıflığı ise verilerdeki aykırı değerlerden oldukça etkilenir.

Bu çalışmada, temel bileşen katsayıları (TBK), ortalama ve standart sapma eğitim verilerinden elde edilmekte ve tüm veri setine uygulanarak temel bileşen vektörü (TBV) hesaplanmaktadır. Temel bileşen katsayıları (TBK) ve vektörlerini (TBV) hesaplamak için kullanılan matematiksel ifadeler kapalı olarak sirasıyla Denk. 11 ve Denk. 12'de verilmiştir.

$$
\begin{aligned}
& T B K_{j}=f_{T B A}\left(z_{i^{*}, j}\right) \quad j=1, \cdots, N j \\
& T B V_{i, j}=\frac{Z_{i, j}-\mu_{Z_{\text {Train }, j}}}{\sigma_{Z_{\text {Train }, j}}} T B K_{j} \quad \begin{array}{l}
i=1, \cdots, N_{i} \\
j=1, \cdots, N j
\end{array}
\end{aligned}
$$

\subsubsection{Makine să̆lık göstergesi}

$\mathrm{Bu}$ bölümde, kullanışlı temel bileşen vektörlerini tek bir sağlık göstergesinde birleştirilmesine odaklanılmıştır. Makine sağlık göstergesi ("health indicator"), bir makine parçasının veya sistemin, sağlıklı durumdan bozulma durumuna geçişi ve sonunda başarısızlıkla sonuçlanan aşamalarını gösterir. Ancak, eğitim aşamasından miras kalan bazı gürültüleri içerir (Orhan vd., 2003; K1zrak vd., 2019). Bu nedenle, yöntemdeki önemli bir adım, kullanışlı temel bileşen vektörleri ile sağlık göstergelerini tahmin etmektir. Bazı temel bileşen vektörleri, sağlıklı bir durumdan başarısızlığa doğru tekdüze bir artış eğilimi göstermez (bkz. Şekil 5). Genellikle bir makine parçasının veya sistemin bozulması eksponansiyel bir artış göstermektedir. Bu nedenle, kullanışlı temel bileşen vektörlerini belirlemek için Denk. 13 yardımıyla tüm öznitelikler $(j)$ için eğim hesaplanır. $\mathrm{Bu}$ eğim eksponansiyel artışı ifade etmete kullanılır. Eğimler hesaplandıktan sonra, en büyük eğimli vektörler kullanışlı temel bileşen vektörler olarak seçilirler. Sağlık göstergesi, her seferinde her bir kullanışlı temel bileşen vektörlerin ortalama değeri alınarak oluşturulur.

$$
e \breve{g} i m_{j}=\frac{1}{N_{i}} \sum_{i=1}^{N_{i}}\left|\frac{T B V_{i, j}-T B V_{N_{i}, j}}{1-N i}\right| \quad j=1, \cdots, N j
$$

\section{Araştırma Sonuçları ve Tartışma}

$\mathrm{Bu}$ çalışmada makine öğrenimi metodolojisi kullanılarak yüksek hızlı rulmanlarda sağlık göstergesinin belirlenmesi amaçlanmıştır. Green Power ABD tarafından gerçekleştirilen ve açık kaynak olacak şekilde araştırmacılara sunulan deneysel titreşim sinyali kullanılmıştır. Bu deney koşullarına göre, her gün örnekleme hızı $97656 \mathrm{~Hz}$ olacak şekilde birbirlerini izleyen 50 gün boyunca yüksek hızda dönen milin şaft yatağındaki rulmandan titreşim sinyali ivme ölçer yardımıyla toplanmıştır (Bkz. Şekil 1). Kaydedilen işlenmemiş titreşim sinyali her bir renk farklı günü temsil edecek biçimde Şekil 2a'da gösterilmiştir. Şekil 2a'da görüleceği üzere titreşim sinyali sırasıyla üç gruba ayrılabilir: (i) sağlıklı çalışma aşaması (0-26 günler arası), (ii) arızalı çalışma aşaması (26-38 günler arası) ve (iii) arıza bozulma aşaması (38-50 günler arası).

Zaman alanındaki titreşim sinyalleri, artan bir sinyal eğilimini ortaya koymaktadır. Öte yandan, welch yöntemi, frekans alanında güç spektral yoğunluğu tahmini için güçlü bir araç olarak kabul edilir. Welch yönteminde kullanılan parametreler sırasıyla; (i) uzunluğu 128 olan dikdörtgensel pencere ("window size"), (ii) 4 pencerenin çakışması ("number of overlap”) ve (iii) titreşim sinyalinin örnekleme hız1 $97656 \mathrm{~Hz}$ ("sampling frequency")'dir. Şekil 2b'de herbir gün için hesaplanan güç spektral yoğunluğu verilmiştir. Her bir gün için maksimum güç spektral yoğunluğu $0.67 \mathrm{~Hz}$ 'de bulunmuş ve maksimum güç spektral yoğunluğu $(63.318 \mathrm{~W} / \mathrm{Hz})$ 49’uncu günde elde edilmiştir.

Titreşim sinyali ivmeölçerler tarafindan ölçüldükten sonra, hataya duyarlı özellikleri ayıklamak üzere titreşim sinyallerinden Tablo 1'de tanımlanan istatiksel öznitelikleri çıkarılmış ve Şekil 3’te gösterilmiştir. Elde edilen istatiksel öznitelikler incelendiğinde genel olarak bir artış gözükmektedir. Bu artan eğilimi iyi gözlemleyebilmek ve özellikleri birbiriyle daha iyi karşılaştırabilmek için z-skor yöntemine göre normalizasyon işlemi yapılmış ve normalize edilmiş öznitelikler Şekil 4'te gösterilmiştir.

Basıklık bir sinyalin tepe noktasının, yani pikin normal dağılımın tepe noktasından daha yüksek veya daha düşük olup olmadığını ölçer. Benzer bir şekilde, çarpıklık, sinyalinin normal durumunun dağılımının soluna veya sağına eğik olup olmadığını ölçer. Şekil 4 incelendiğinde, zaman alanında çarpıklık gün geçtikte artarken, basıklık arıza meydana gelene kadar sabit bir değer (0 genlik değerleri) etrafında dalgalanmaktadır (Bkz. Şekil 4). Böylece erken dönemde sağlık göstergesinin tahmini zorlaştıracaktır. Deney sonuçlarından elde edilen zaman alandaki titreşim daha önce üç gruba ayrılmıştı ve frekans alanındaki basıklığa ve çarplıklığa bakıldığında sağlıklı çalışma alanından arızalı çalışma analına geçiş (26. gün) net bir şekilde belirmektedir. 

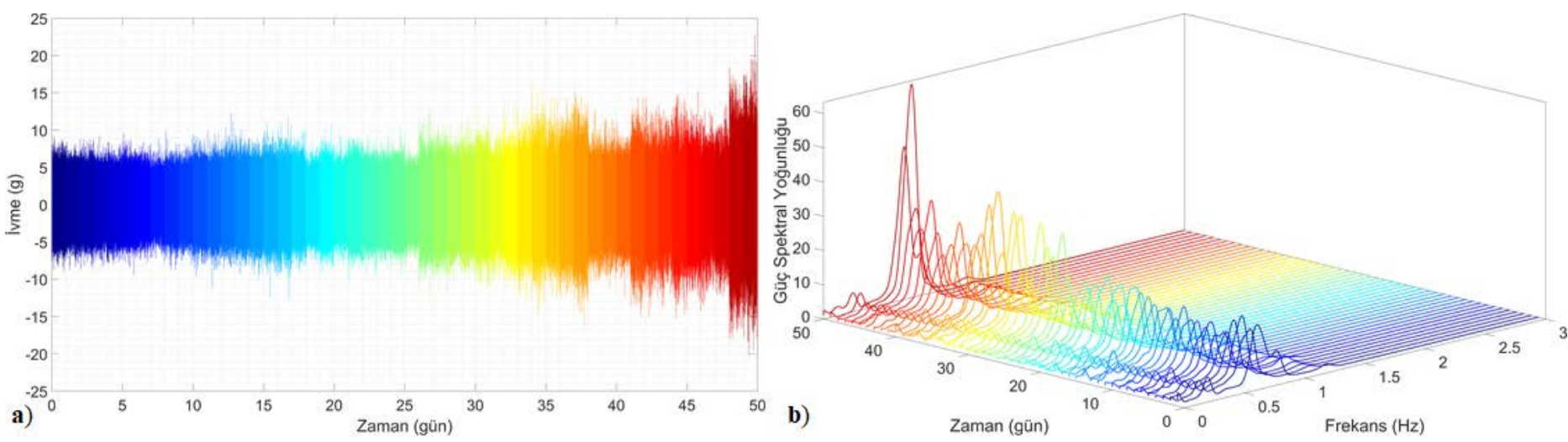

Şekil 2. a) Işslenmemiş titreşim sinyali (zaman alanı), b) güç spektral yoğunluğu (frekans alanı)

Buna ek olarak, etkin değer, bir sinyalin güç içeriğini gösterir ve hem zaman alanında hem de frekans alanında sinyalin gücü artmaktatır. Ayrıca, tepe faktörü, genellikle bir hata durumunun erken aşamalarını tespit etmede yararlıdır. Etki faktörü, titreşim sinyalinde üretilen bir hatanın etkisinin ölçülmesinde faydalıdır. Tepe ve etki faktörleri hem zaman alanında hem de frekans alanında paralellik göstermekte arıza durumuna yaklaştıkça artmaktadır. Buna ek olarak, arızanın gerçekleştiği günde (49'uncu günde) etkin değer hem zaman hem de frekans alanında en yüksek değere (11 genlik değerine) ulaşmıştır. Fakat, arıza bozulma aşamasında (42’nci günde) tüm özniteliklerde ani bir düşüş görülmüştür. Bunun nedeni, rejimler arası geçişte genliğinin azalmasıdır (Bkz. Şekil 2a).

Savitzky-Golay yöntemi ile eğitim ve ölçüm aşamasından miras kalan tüm özniteliklerdeki gürültüler giderilmiş ve düzeltilmiş (“smooth”) öznitelikler Şekil 4'te gösterilmiştir. Düzeltilmiş özniteliker esas alınarak TBA yöntemi ile TBV hesaplanmıştır. Her bir TBV, her bir özniteliğe karşılık gelmemekte, aksine Savitzky-Golay yöntemiyle düzeltilmiş tüm öznitelikler TBV üzerine projeksiyon yaparak ifade edilmektedir. Denk. 11 ve Denk. 12'e göre hesaplanan TBV'ların 50 gün boyunca gelişimi Şekil 5 'te verilmiştir.

Tüm TBV'ler, Z-skoru normalizasyonu kullanılarak aynı ölçekte çizilebilir, böylece birbirleri ile karşılaştırmak daha kolay olur. TBV'ler incelendiğinde 30'uncu günde bir sıçrama gözükmektedir. Bunun sebebi eğitim için ayrılan \%60'llk kısımın etkisini TBV göstermesidir. Bundan başka TBV 1,4,8 ve 9 eksponansiyel artış göstermekte olup ve potansiyel sağlık göstergeleri olarak seçilebilir. Fakat, TBV 4 ve TBV 9'da 10'uncu ve 30'uncu günler arasında, eğitim setinde olmasına rağmen, ters yönde bir eğim mevcuttur. İlaveten, TBV 8'de 30'uncu güne kadar sabit bir durum söz konusudur. Sağlık göstergesi monoton bir artış göstermesi gerekmektedir. Dolaysıyla, TBV 1 kestirimci bakım ve kalan faydalı ömür hesabında kullanılmak üzere potansiyel sağlık göstergesi olarak seçilebilir.
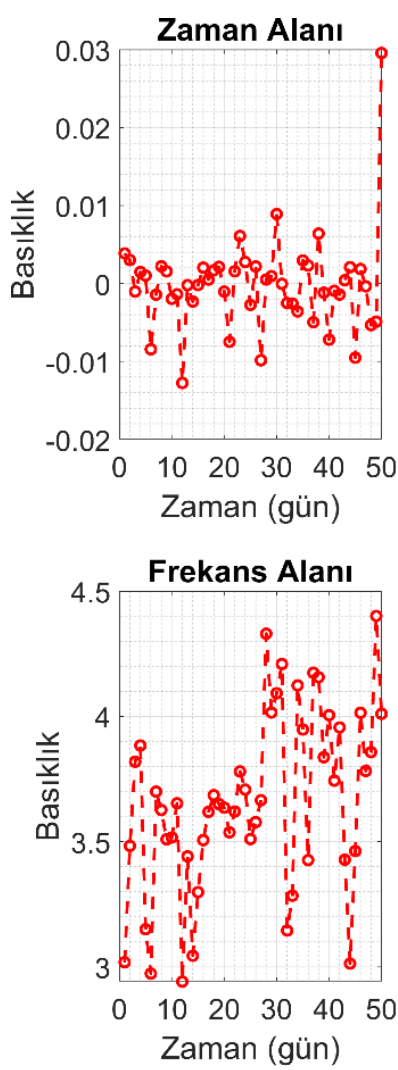
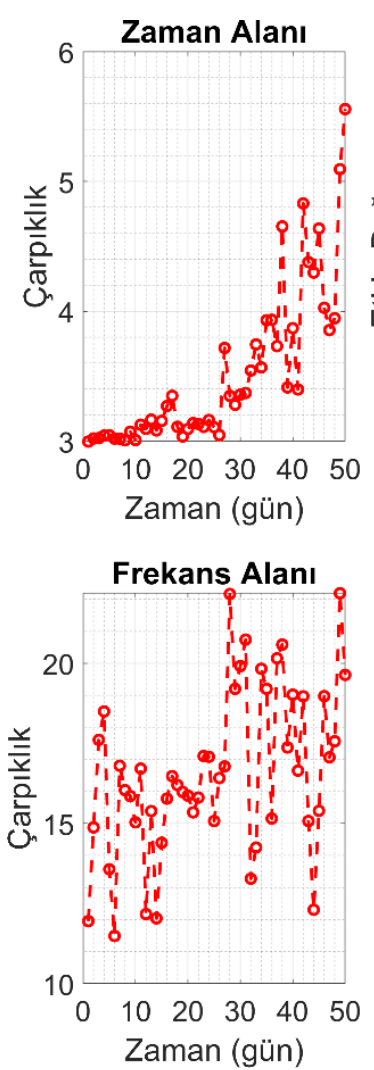
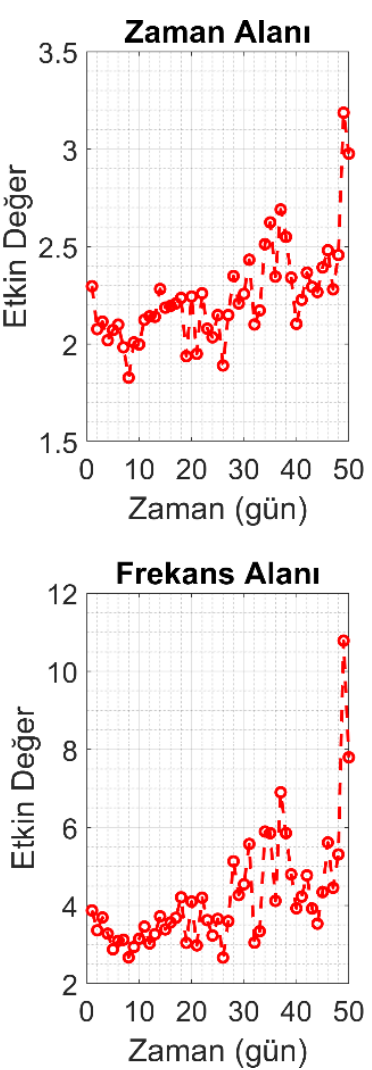
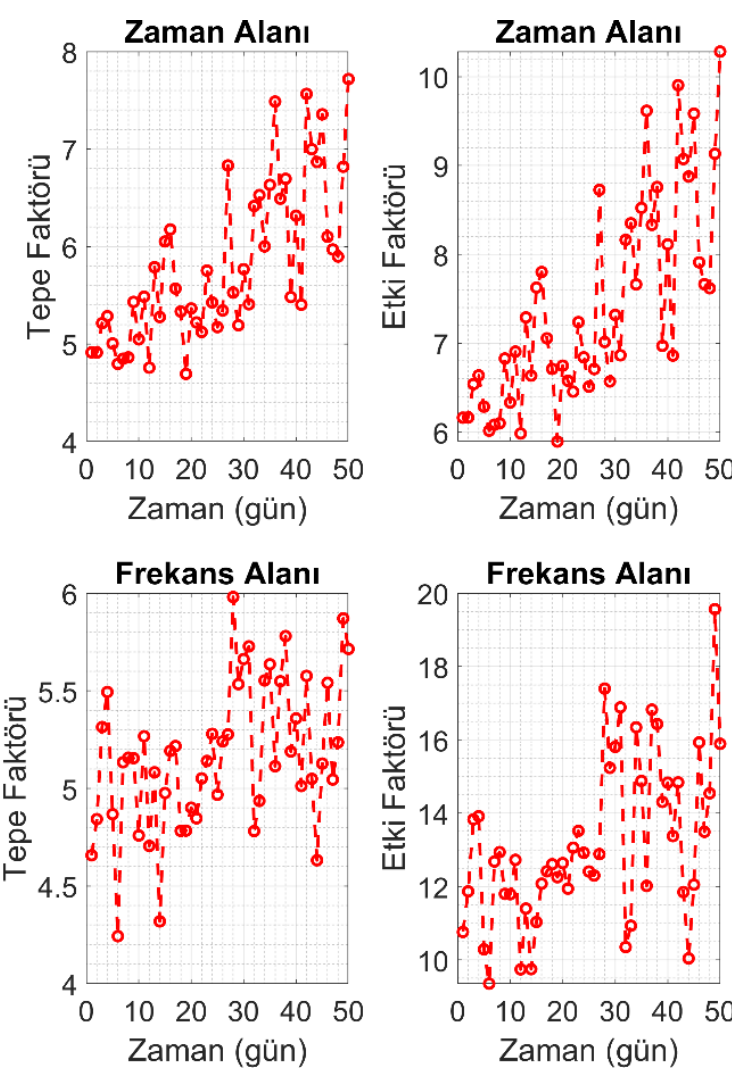

Şekil 3. Zaman ve frekans alanlarındaki istatiksel özniteliklerin 50 gün boyunca gelişimi 
European Journal of Science and Technology
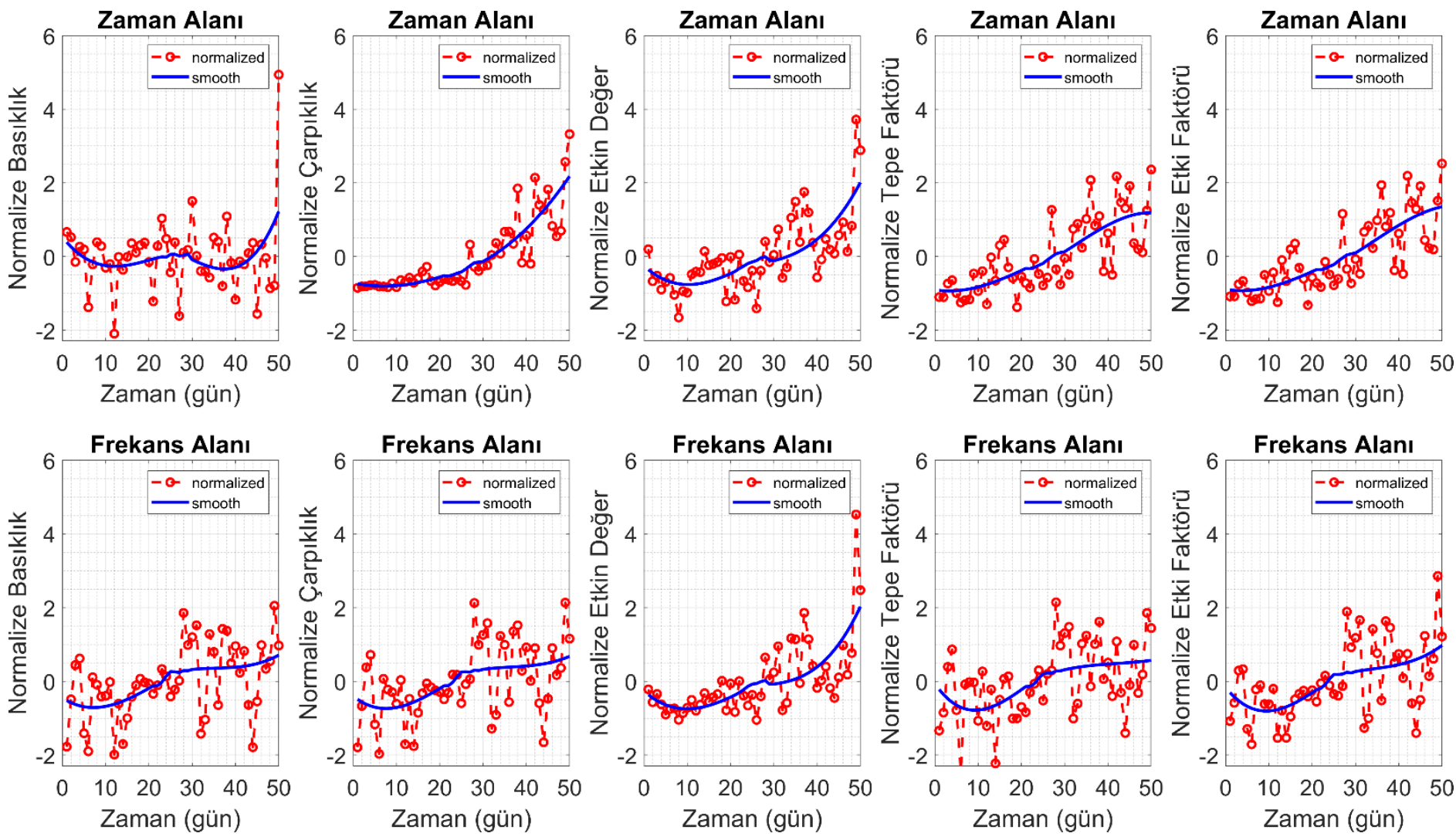

Şekil 4. Normalize edilmiş istatiksel özniteliklerin 50 gün boyunca gelişimi

TBV 1

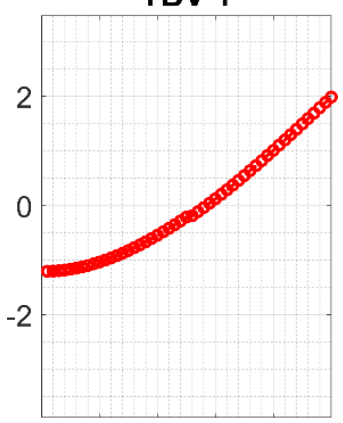

$\begin{array}{llllll}0 & 10 & 20 & 30 & 40 & 50\end{array}$

Zaman (gün)

TBV 6

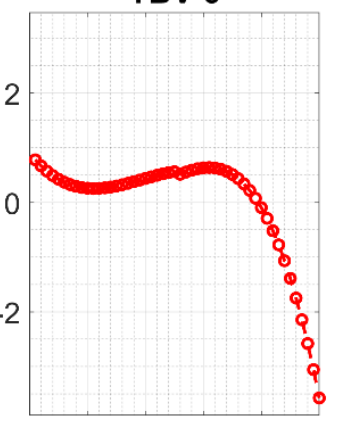

$1020 \quad 30 \quad 4$
Zaman (gün)
TBV 2

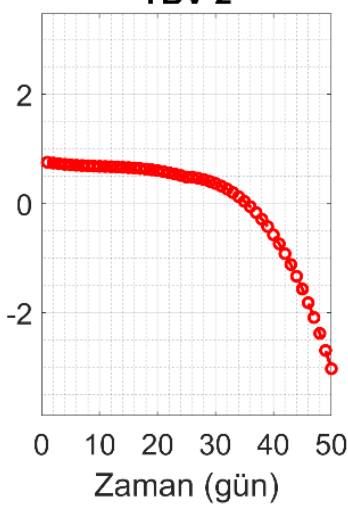

TBV 7

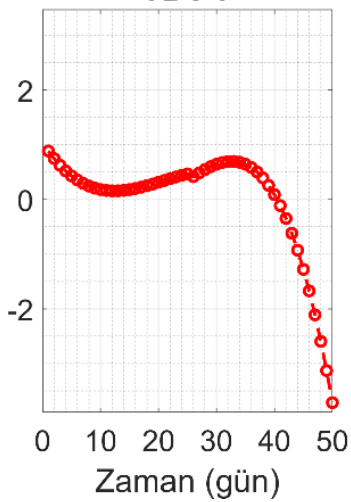

TBV 3

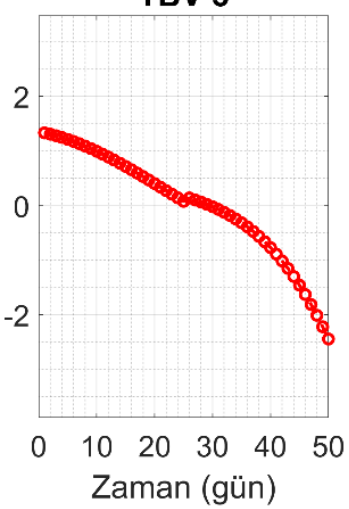

TBV 8

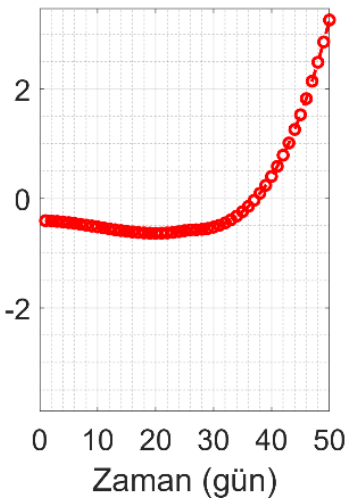

TBV 4

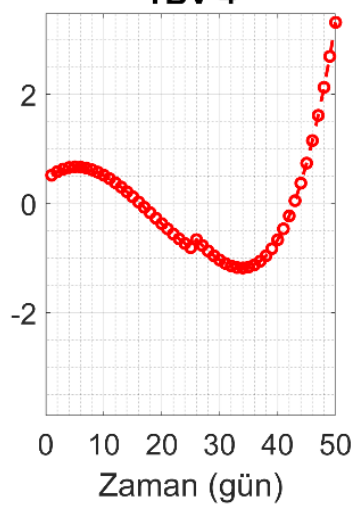

TBV 9

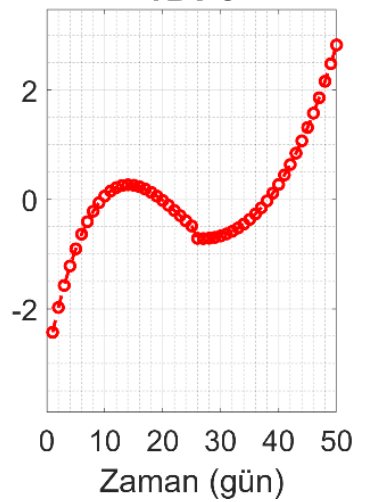

TBV 5

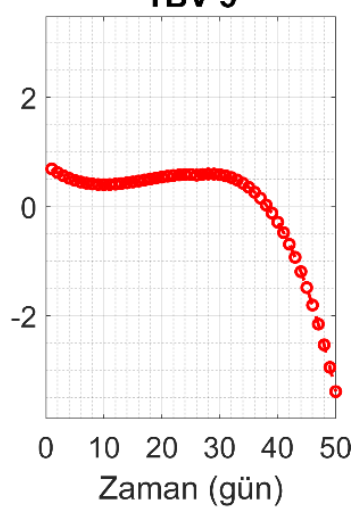

TBV 10

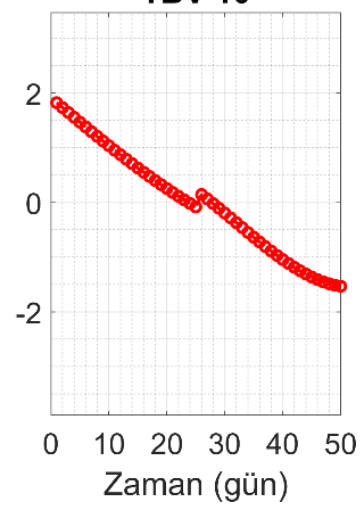

Şekil 5. Temel Bileşen Vektörlerin (TBV) 50 gün boyunca gelişsimi 


\section{Avrupa Bilim ve Teknoloji Dergisi}

Titreşim sinyalleri Green Power ABD tarafindan gerçekleştirilen deney vasıtasıyla yüksek hızda çalışmak için tasarlanmış rulmandan elde edilmiştir (Ali vd., 2017; Saidi vd., 2017). Yürüttükleri deneyde rulmanın 5'inci günde bozulmaya başladığı, 49'uncu günde ise tamamen bozulduğu ("time to failure") tespit edilmiştir. $\mathrm{Bu}$ deney sonucunda ise rulmanın KFÖ'nün lineer olarak hergün 1 gün eksilecek şekilde azaldığ 1 belirlenmiştir. $\mathrm{Bu}$ çalışmanın amacı, kestirimci bakımda kullanılmak için sağlık göstergesinin tespitidir. Tespit edilen sağlık göstergesi eksponansiyel bozulma modelinde kullanılarak rulman için KFÖ tahmin edilmiştir. Makine öğrenmesi metodolojisi kullanılarak tahmin edilen KFÖ, deneysel olarak belirlenen gerçek KFÖ ile karşılaştırılarak tespit edilen sağlık göstergesinin başarısı belirlenmiştir.

Şekil 6'da tahmin edilen ve deneysel olarak belirlenen gerçek KFÖ gösterilmiştir. Tahmin edilen KFÖ'yu iki ana bölüme; (i) eğitim veri seti kullanılarak tahmin (5'inci ve 30 'uncu günler arası) ve (ii) test veri seti kullanılarak tahmin (30’uncu ve 50'nci günler) diye ayırabiliriz. Ayrıca, eğitim veri seti kullanılarak tahmini de iki sınıfa bölmekte münkündür. $\mathrm{Bu}$ iki sınıf 5'inci ve 15'inci günleri kapsayan prior eğitim seti ve 15 'inci ve 30'uncu günleri kapsayan posterior eğitim setidir. Şekil 6'da görüldüğü gibi 5'inci ve 15'inci günleri arasında KFÖ tahmini gerçek KFÖ'den uzakken daha fazla veri noktası mevcut oldukça tahmin daha doğru hale gelmektedir.

İstatistikte sıklıkla kullanılan determinasyon katsayısı $\left(\mathrm{R}^{2}\right)$ ve kök ortalama kare hata (RMSE) değerleri ile KFÖ tamninin ve dolaysıyla seçilen sağlı göstergesinin başarısı prior eğitim seti, posterior eğitim seti ve test seti için tespit edilmiştir. Buna göre, prior eğitim setinin $\mathrm{R}^{2}$ ve RMSE değerleri sirayıla 0.6625 ve 17.8925; posterior eğitim setinin $\mathrm{R}^{2}$ ve RMSE değerleri sırayıla 0.9947 ve 1.7688 ; test setinin $R^{2}$ ve RMSE değerleri sırayıla 0.9897 ve 2.2025 'tir. Eğitim veri setinin için elde edilen $\mathrm{R}^{2}$ ve RMSE değerleri, test veri seti için elde edilenlerden daha iyi olmasının sebebi 15'inci - 30'uncu günler arasında makine ögrenmesinin gerçekleşmesi ve 30'uncu günden sonra KFÖ'nün bu öğrenme ile hesaplanmasıdır.

\section{Sonuç}

$\mathrm{Bu}$ çalışmada kestirimci bakımda kullanılmak üzere sağlık göstergesi bulunması amaçlanmıştır. Arıza artış aşamalarının tanımlanması için ivmeölçer kullanılarak ölçülen titreşim sinyallerine sirasıyla Welch yöntemi, temel istatistiksel öznitelikler ve temel bileşenler analizi yöntemi uygulanmış ve temel bileşen vektörleri bulunmuştur. Sonrasında, bu vektörlerden monoton eksponensiyel artış eğilimine en iyi uyan vektör seçilerek bozulmayı temsil etmek için sağlık göstergesi belirlenmiştir. Bu çalışmada, iyi bir kalan faydalı ömür tahmini yapmak için ilk önce iyi bir sağlık göstergesini hesaplanması gerektiği belirtilmiştir. Bunu kanıtlamak içinde tahmin edilen kalan faydalı ömürü gerçek deney sonuçları ile karşılaştırılmıştır. Sonuçlardan görüleceği gibi posterior eğitim setinde oldukça yüksek neredeyse birebir korelasyon sağlanmıştır $\left(\mathrm{R}^{2}\right.$ ve RMSE değerleri sırayıla 0.9947 ve 1.7688 ). Bunun sebebi eğitim setinin tüm verleri bu noktada makine öğrenmesinde kullanılmasıdır. Diğer yandan, test veri setine bakıldığında, $\mathrm{R}^{2}$ ve RMSE değerleri sırayıla 0.9897 ve 2.2025 elde edilmiş ve tahmin edilen KFÖ her zaman gerçek KFÖ’ün altında çıkmıştır. Böylece, herhangi bir arıza olmadan şaft yatağındaki rulmana müdehale edilebilmekte ve bakımı yapılabilmektedir.

Kestirimci bakım yöntemleri karar alıcılar açısından belirsizlik durumunu azaltmaktadır. Arızaları belirlemede sistemin ürettiği durum verileri (titreşim, akustik, termal, vb.) değerlendirme işini otomatikleştirmeye dönük çalışmalar makine öğrenmesi metotları (temel bileşenlerin tespiti, sınıflandırma, yapay sinir ağları, vb.) kullanılarak geliştirilebilir. Doğru karar sonucu yapılan işlemler; işletmelerin makine, yedek parça ve personel verimliliğine katkıda bulunmaktadır. $\mathrm{Bu}$ çalışmayla yüksek hızlı rulmanlar ve benzer şekilde titreşim üreten sistemlerde durum verileriyle sağlı göstergesinin tanımlanabileceği gösterilmiştir. Bu sebeple, öne sürülen metot kestirimci bakım için önemli bir potansiyele sahip olup ve kalan faydalı ömür tahmininde kullanılabilir. Dolayısıyla, gelecekteki çalışmalarda, dişli kutusu tasarımlarında arıza tespiti için bu yöntem araştırılacaktır.

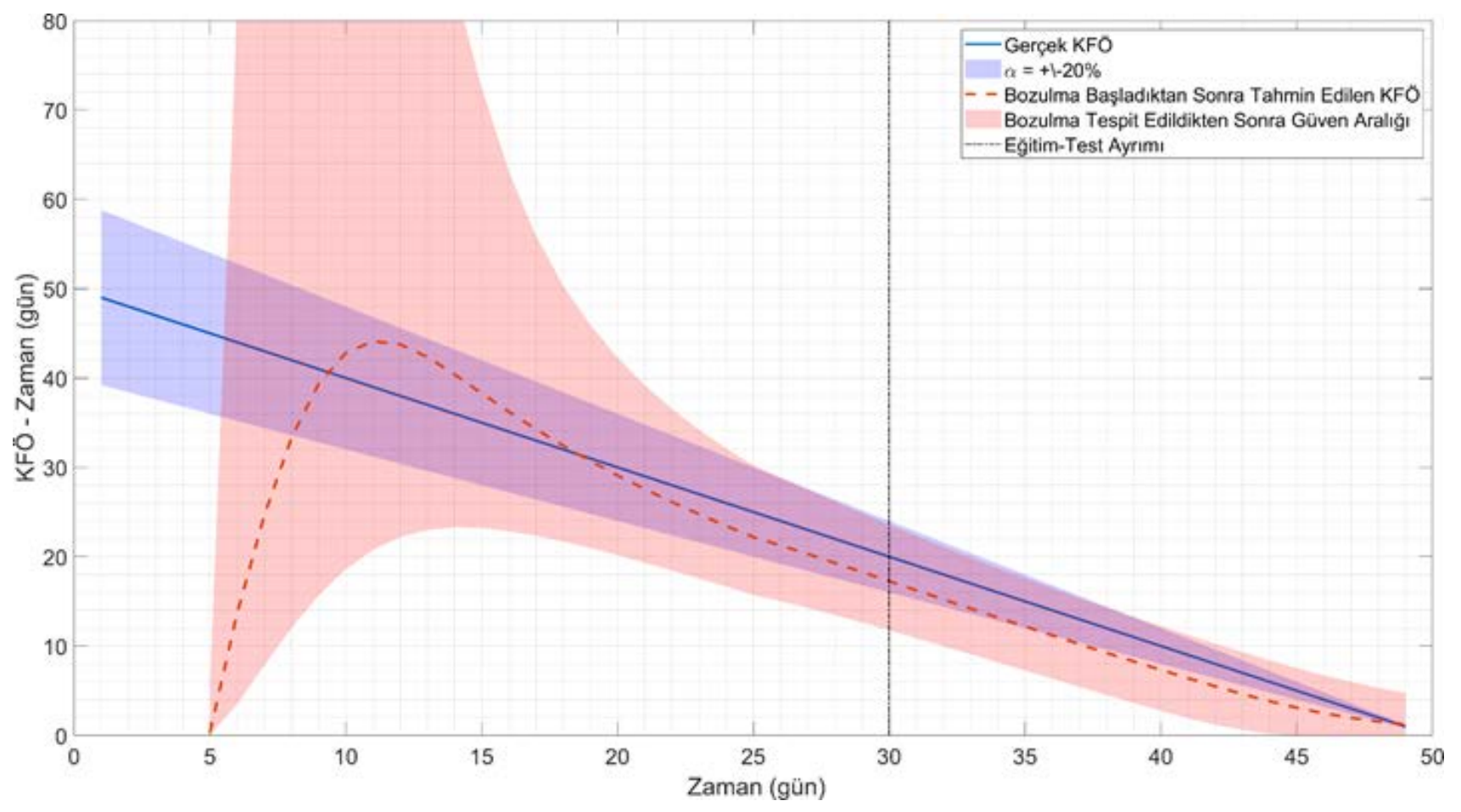

Şekil 6. Sağlık göstergesi kullanılarak kalan faydalı ömür (KFÖ) tahmini ve gerçek KFÖ 


\section{Kaynakça}

Abdelli, K., Grießer, H., \& Pachnicke, S. (2020). Machine Learning Based Data Driven Diagnostic and Prognostic Approach for Laser Reliability Enhancement. In 22nd International Conference on Transparent Optical Networks (ICTON) (pp. 1-4). IEEE.

Akçay, H., \& Türkay, S. (2019). Power spectrum estimation in innovation models. Mechanical Systems and Signal Processing, 121, 227-245.

Ali Ben, J., Saidi, L., Harrath, S., Bechhoefer, E., \& Benbouzid, M. (2018). Online automatic diagnosis of wind turbine bearings progressive degradations under real experimental conditions based on unsupervised machine learning. Applied Acoustics, 132 (2017), 167-181.

Banerjee, A., Gupta, S. K., \& Datta, D. (2020). Remaining Useful Life as a Cognitive Tool in the Domain of Manufacturing. In Emotion and Information Processing (pp. 171-183). Springer, Cham.

Bektaş, O. (2020). Kestirimci Bakım İçin Döner Mekanizma Bozulma Eğrisinin Tanımlanması. European Journal of Science and Technology, 420-428.

Elasha, F., Shanbr, S., Li, X., \& Mba, D. (2019). Prognosis of a wind turbine gearbox bearing using supervised machine learning. Sensors (Switzerland), 19(14), 1-17.

Guo, Y., Na, J., Li, B., \& Fung, R. F. (2014). Envelope extraction based dimension reduction for independent component analysis in fault diagnosis of rolling element bearing. Journal of Sound and Vibration, 333(13), 2983-2994.

Jin, X., Wang, Y., \& Hong, W. (2019). Power Spectrum Estimation Method Based on Matlab. In Proceedings of the 3rd International Conference on Vision, Image and Signal Processing (pp. 1-5).

Kappal, S. (2019). Data Normalization Using Median Median Absolute Deviation MMAD based Z-Score for Robust Predictions vs. Min-Max Normalization. London Journal of Research in Science: Natural and Formal.

Kızrak, M. A., \& Bolat, B. (2019). Uçak Motoru Sağlı̆ğ için Uzun-Kısa Süreli Bellek Yöntemi ile Öngörücü Bakım. International Journal of InformaticsTechnologies, 12(2).

Kollmann, S., Estaji, A., Bratukhin, A., Wendt, A., \& Sauter, T. (2020). Comparison of Preprocessors for Machine Learning in the Predictive Maintenance Domain. In IEEE 29th International Symposium on Industrial Electronics (ISIE) (pp. 49-54). IEEE.

Liu, H., \& Han, M. (2014). A fault diagnosis method based on local mean decomposition and multi-scale entropy for roller bearings. Mechanism and Machine Theory, 75, 6778.

Liu, Z., \& Zhang, L. (2020). A review of failure modes, condition monitoring and fault diagnosis methods for large-scale wind turbine bearings. Measurement, 149, 107002.

Muratet, L., Doncieux, S., \& Meyer, J. A. (2004). A biomimetic reactive navigation system using the optical flow for a rotary-wing UAV in urban environment. Proceedings of the International Session on Robotics, 2262-2270.

Orhan, S., Aktürk, N., \& Çelik, V. (2003). Bir santrifüj pompa rulmanlarının çalışabilirliğinin titreşim analizi ile belirlenmesi. Gazi Üniversitesi Fen Bilimleri Dergisi, 16(3), 543-552.

Ozkat, E. C. (2019). “The Comparison of Machnine Learning Algorithms in Estimation of Remaining Useful Life.” In IX. International Maintenance Technologies Congress. pages, 614-619. Denizli, Turkey: UCTEA CHAMBER OF MECHANICAL ENGINEERS, ISBN NO: 978-605-011288-7

Saidi, L., Ben Ali, J., Bechhoefer, E., \& Benbouzid, M. (2017). Wind turbine high-speed shaft bearings health prognosis through a spectral Kurtosis-derived indices and SVR. Applied Acoustics, 120, 1-8.

Sun, W., Yang, G. A., Chen, Q., Palazoglu, A., \& Feng, K. (2013). Fault diagnosis of rolling bearing based on wavelet transform and envelope spectrum correlation. JVC/Journal of Vibration and Control, 19(6), 924-941.

Tao, X., Ren, C., Wu, Y., Li, Q., Guo, W., Liu, R., ... \& Zou, J. (2020). Bearings fault detection using wavelet transform and generalized Gaussian density modeling. Measurement, 155, 107557.

Teng, W., Zhang, X., Liu, Y., Kusiak, A., \& Ma, Z. (2017). Prognosis of the remaining useful life of bearings in a wind turbine gearbox. Energies, 10(1).

Tibaduiza, D. A., Mujica, L. E., \& Rodellar, J. (2011). Structural Health Monitoring based on principal component analysis: damage detection, localization and classification. Advances in Dynamics, Control, Monitoring and Applications, Universitat Politècnica de Catalunya, Departament de Matemàtica Aplicada, 3(1), 8-17.

Villwock, S., \& Pacas, M. (2008). Application of the welchmethod for the identification of two- and three-masssystems. IEEE Transactions on Industrial Electronics, 55(1), 457-466.

Yıldı, K., Çamurcu, Y., \& Doğan, B. (2010). Veri madenciliğinde temel bileşenler analizi ve Negatifsiz matris çarpanlarına ayırma tekniklerinin karşılaştırmalı analizi. Akademik Bilişim, 10-12. 